\section{Differentiating clinical care from disease prevention: a prerequisite for practicing quaternary prevention}

\author{
Diferenciando o cuidado clínico da prevenção \\ de doença: um pré-requisito para praticar a \\ prevenção quaternária
}

\section{Diferenciando el cuidado clínico de la prevención de la enfermedad: un prerrequisito para la práctica de la prevención cuaternaria}

Charles Dalcanale Tesser 1,2 Armando Henrique Norman 3

\begin{abstract}
This article contends that the distinction between clinical care (illness) and prevention of future disease is essential to the practice of quaternary prevention. The authors argue that the ongoing entanglement of clinical care and prevention transforms healthy into "sick" people through changes in disease classification criteria and/or cut-off points for defining high-risk states. This diverts health care resources away from those in need of care and increases the risk of iatrogenic harm in healthy people. The distinction in focus is based on: (a) management of uncertainty (more flexible when caring for ill persons); (b) guarantee of benefit (required only in prevention); (c) harm tolerance (nil or minimal in prevention). This implies attitudinal differences in the decision-making process: greater skepticism, scientism and resistance towards preventive action. These should be based on high-quality scientific evidence of end-outcomes that displays a net positive harm/benefit ratio.
\end{abstract}

Quaternary Prevention; Disease Prevention; Medical Care

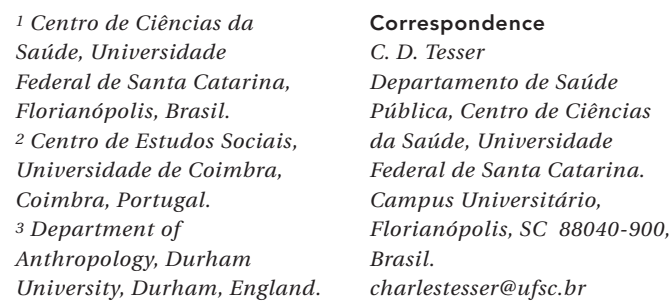

${ }^{1}$ Centro de Ciências da Saúde, Universidade Federal de Santa Catarina, Florianópolis, Brasil. 2 Centro de Estudos Sociais, Universidade de Coimbra, Coimbra, Portugal. ${ }^{3}$ Department of Anthropology, Durham University, Durham, England.

charlestesser@ufsc.br 


\section{Introduction}

Quaternary prevention (P4) are the actions taken for identifying people at risk of over-medicalization, in order to protect them from new medical invasion and to propose ethically acceptable alternatives. The aim is to protect users of health services from inappropriate and iatrogenic interventions 1,2. Other meanings for $\mathrm{P} 4$ have been proposed, as summarized by Starfield et al. ${ }^{3}$, and its importance to the Brazilian Unified National Health System (SUS) can be found in Norman \& Tesser 4

As defined above, $\mathrm{P} 4$ has a relevant role within health systems since it can contribute to reorganizing the quality standards of care with the aim of reducing excess medicalization and iatrogenic effects. Essentially, it refers to a practical-technical and professional by-product of a well-known criticism and knowledge about society's medicalization processes discussed by authors such as Foucault 5, Illich 6, Zola 7, Szasz 8, Skrabanek 9,10, and Clarke et al. 11.

By focusing on the clinical and healthcare practice, it is possible to circumvent the problems, contradictions, and limits of the P4 proposal. For instance, being conceptually and complementarily inserted in Leavell \& Clarke's problematic and questionable disease natural history model 12 , P4 could theoretically mean a reinforcement of what it intends to reform, limit or even transform. However, as a critical synthesis stemming from primary health care professionals, the $\mathrm{P} 4$ proposition can lead to changes in preventive practices at all levels of prevention, by suggesting attitudes and systematizing the available scientific knowledge for coping and managing the overemphasis on prevention, medicalization, and its excessive iatrogenic effects 4 . Thus, $\mathrm{P} 4$ is considered here as actions that realize practical and technical developments towards an ethical, attitudinal, epistemological, and political resistance to the excesses of medicalization, preventivism, and iatrogenic effects in clinical and institutional settings. Note that there is no intention of proposing something that is conceptually new. The relevance and innovativeness reside in its practical focus.

The creation of terms that synthesize discussions and theories is common in health professional environments. In this regard, the abbreviated acronym for quaternary prevention (P4) makes it even simpler to convey its ideas than the three quoted lines above. This linguistic pragmatism facilitates communicating with primary health care professionals, usually responsible for caring for the country's entire population in universal public health systems with strong primary health care provision, as intended by the SUS 4 . Thus, the P4 concept fosters the systematization and development of practical and technical frameworks with regards to the discussions on excesses of bio-medicalization and preventive care. This is relevant to the everyday practice of health professionals and institutions, but also to health related disciplines in undergraduate and postgraduate courses.

In this context, we contend that the practice of $\mathrm{P} 4$ requires the distinction between clinical care of the sick and preventive actions in asymptomatic, i.e. specific primary and secondary prevention 12 , such as disease screening. This distinction gains contemporary relevance and deserves renewed attention due to developments in clinical epidemiology and evidence-based medicine (EBM) around the "risk" categories 13,14 which are being progressively managed as diseases 3 . This has medicalized risk factors, produced pre-disease states, and encouraged disease marketing (disease mongering) 15,16,17,18.

The operational consequences of this process on medical practice and knowledge meant that prevention (future disease) has gradually been absorbed and metamorphosed into the clinical care of the sick. Therefore, clinical prevention has gained prominence and progressively amplified its scope within health professionals' practices ${ }^{3}$. In this context, demands on health systems for adopting preventive and therapeutic clinical interventions have increased. Such in duced demands are largely disconnected from the patients' illness narratives (in the case of prevention), but also consume much of the health professionals' time 3,19. Moreover, a number of preventive activities that are being adopted lack required high-quality scientific evidence standards, carrying the potential of causing harm to both health systems (by inappropriate use of public resources) and the population's health 20 . This is particularly important to primary care professionals' and policy-makers' decision-making processes since there are enormous pressures to implement disease prevention and health promotional initiatives as mainstream policies in public funded health care systems 21 .

In this article, we analyze the distinction between curative (clinical care) and preventive actions in biomedicine by drawing on ideas and concepts that are found in the literature. This distinction is systemized in three main topics: (a) the biomedical process of merging prevention into clinical care; (b) technical-ethical differences of these two health care activities; and (c) the attitudinal implication for both policy-makers and health professionals by establishing this distinction. These interconnected topics highlight 
the importance of maintaining the distinction between prevention and clinical care as a prerequisite for applying $\mathrm{P} 4$ actions in prevention. By establishing this distinction as a sine qua non condition for good quality preventive care, we hope to contribute and deepen the discussions in the field of disease prevention.

\section{Unsustainable and dangerous fusion}

Blurring the distinction between curative and preventive actions has been a long and ongoing process in biomedicine; it has not been considered a philosophical, theoretical or even rare phenomenon. It draws on biomedical knowledge of the construct of diseases and risk management, by mixing prevention with treatment of pathological conditions. Current treatment of heart failure illustrates the case of how prevention is being absorbed into disease management clinics, thereby making its distinctive features more obscure.

In the past, heart failure classification was based on the disease's symptom severity organized in four stages 22: symptoms triggered only by exertion (Grade I); symptoms triggered by everyday activities (Grade II); symptoms triggered at the slightest effort (Grade III); symptoms at rest (Grade IV). Subsequently, another classification for heart failure was created, systematized by the disease's progression: the four stages, A, B, $\mathrm{C}$ and $\mathrm{D} 23$. For instance, $\mathrm{A}$ and $\mathrm{B}$ are symptomless stages of heart failure. Stage A includes patients "at risk of developing heart failure" 24 (p. 7), whereas in stage B patients have "cardiac structural damage, but still no symptoms" 24 (p. 7).

The new heart failure classification added two pre-disease categories in order to identify eligible patients for preventive interventions. The expansion of the pathological definition for preventive purposes is feasible in many other situations and diseases. This process prepares the background for adding preventive therapeutic approaches, including pharmacological issues, to be managed along the lines of the disease treatment framework. As the use of drugs for disease prevention entails the "treatment" of a great number of "patients" with the disease's risk profile, it exposes potentially asymptomatic individuals to serious harm 25 .

The heart failure example reproduces the biomedical trend in disease definition (in this case a syndrome). Identifiable changes in the body's structural/functional properties are used for establishing the disease's diagnostic standard criteria. This process allows for a great degree of conventionalism, which tends to become in- creasingly comprehensive, as the capacity and resolution of biotechnological devices have improved. Nevertheless, the ability to detect minor structural and functional changes increases the chances of dissociated clinical findings: technological diagnostic results that have no clinical relevance. This is a common occurrence in patients with low back pain (without red flags) and tomographic studies that show clinically irrelevant radiological findings 26 .

Once the classification criteria and the associated standard management approach (including pharmacological) have been established, therapeutic innovations tend to be quickly disseminated. Nevertheless, if further evaluation shows no advantage in intervention, it can take years or decades to withdraw it from clinical practice. There are several examples of this continued "misuse" of biotechnologies such as requesting $\mathrm{X}$-rays for low back pain and headaches, as well as antibiotic prescription both for acute diarrhea and acute otitis in young children. The changes in disease classification and cut-off points for defining hypertension, diabetes, cholesterol, and mental disorders follow the same trend seen in the case of heart failure, making these health conditions increasingly comprehensive by labelling more people as sick, and consequently, generating predictable and unpredictable harm.

The lack of a clear distinction between preventive and curative interventions leads to the perception that preventive initiatives are harmless or benign. Thus, the criteria used for deciding whether to adopt a preventive initiative might not be as rigorous as the criteria used when caring for the sick. This process strongly induces medicalization and increases iatrogenic harm, hence the need for P4 actions. In other words, we need to be more skeptical, tough and critical towards disease prevention interventions that operate by lowering cut-off points and/or by redefining diagnostic criteria that includes asymptomatic people. This also applies to preventive therapeutic targets that are based on lower levels of biochemical parameters as in the case of glycated hemoglobin (HbAlc) for diabetic control, as a sign of optimum clinical care management. In fact, Currie et al. 27 found an increased mortality in patients whose HbAlc targets were greatly reduced.

The critical approach to the enmeshment of prevention and cure is based on conceptual advances in health and biomedicine. This includes dynamic approaches to health-disease processes, where the flows of influence and causation are multidirectional and complex 28 . A dynamic approach values and recognizes humans' adaptive processes of self-healing and/or 
auto-regulation. It also acknowledges the mutual influences that society, the environment, and the various levels of human beings' organization have in producing health-disease processes. By recognizing the complexity of prevention, a dynamic approach questions the disease causation path that focuses strictly on the localized bodily structural/functional changes, which are the basis for both pathophysiological biomedical models and preventive interventions for isolated risk factors. This dynamic approach challenges the materialistic-mechanistic diseases construct and the (uni-) multi-linear disease causation chain inherited from the anatomic-clinical and Pasteurian revolution 29. Thus, the biomedical model is facing important limitations and problems due to an increase in iatrogenic harm 30 and the excessive biomedicalization 11 of health care via centrally driven policies that focus on disease management rather than patients' needs 31,32 .

The growing debates on overdiagnosis and overtreatment are examples of the relevance of the theoretical and practical problems found in preventive initiatives. Overdiagnosis and overtreatment occur when a disease is correctly diagnosed (including cancer), but it would have no clinical impact to the person's life 33 . This has enormous implications for public health as recently synthesized by Bulliard \& Chiolero 34 . Contrary to the beliefs induced by the natural history model of diseases, there is strong evidence that overdiagnosis is more common than one would have thought, and this is particularly true in cancer screening 35 . Since 2013, international conferences on overdiagnosis and overtreatment are being held to tackle this phenomenon (http:// www.preventingoverdiagnosis.net/). The overdiagnosis, especially in cancers, tends to generate overtreatment (which is pure harm), since currently it is impossible to differentiate which early detected "disease" would eventually manifest. Overdiagnosis is counter-intuitive and imperceptible to professionals and patients, as well as a challenge to the biomedical model.

When properly justified, specific preventive actions can and should be performed, as well as therapeutic approaches aimed at detectable lesions on the materiality of the body, as in myocardial infarction, tuberculosis, bacterial meningitis, trauma, etc. However, this approach is insufficient and problematic in most prevalent chronic (and some acute) health problems responsible for the largest part of the morbidity and mortality burden of collective diseases, especially when aiming to impact them through the ideal of preventive medicine that is "precise" and individualized 36 .

\section{Technical and ethical considerations}

The technical and ethical requirements for deciding on preventive disease recommendations are very different from those of clinical care of illness (with or without pain) 37,38 . In this regard, three interconnected aspects are especially relevant: the uncertainty management threshold, guarantee of results, and the harm tolerance threshold.

In the context of illness care (present suffering), health professionals are allowed a reasonable degree of diagnostic and therapeutic interventions, even when facing situations of significant uncertainty. This higher uncertainty management threshold is accepted as part of the benevolent duty of professionals. This is a trade-off situation, organized around patients' potential curative and/or relief prospect (benefit) that urges for therapeutic actions. In this case, a relatively higher tolerance threshold to medical interventions' adverse effects exists. In other words, potentially unintended harmful consequences, which may affect patients' health, are balanced against patients' healing and/or suffering relief perspective. In clinical care scenarios, it is difficult to request or predict favorable outcomes. What we expect is technical correctness and ethical professionalism 4 .

Nevertheless, in preventive interventions a lower uncertainty management threshold is required as part of the professionals' non-malevolence duty. The harm tolerance threshold is much lower for preventive actions. In prevention, the balance between harms and benefits is hypothetical/probabilistic as the disease events are projected in the future. In this forecasting mechanism, population studies and/or population modelling are used to infer the intervention's benefit to a particular individual ${ }^{39}$. This is very problematic given the individuals' low susceptibility prior to the preventive intervention. Thus, in prevention both harm tolerance and uncertainty management thresholds are radically distinct from clinical situations, since prevention is practically the only context in which harm can occur without any potential benefit 38 (Table 1; situation D).

In the population, disease prevalence is generally low $(<1: 1,00040)$, except for very few conditions such as diabetes and hypertension. Also the proportion of people who become ill at any given point in time for a particular disease (for which there is a specific preventive action) is very small. Thus, the group D may be much more significant and/or even greater than group A $+C$, if we include the spectrum of potential harm described in the footnote of Table 1. However, most often 
Potential consequences of preventive interventions on asymptomatic individuals.

\begin{tabular}{lcc}
\hline Adverse effects of preventive actions (harms) * & $\begin{array}{c}\text { Potential for developing a future disease } \\
\text { Present }\end{array}$ \\
\hline Do not occur & A & B \\
Occurs & C & D \\
\hline
\end{tabular}

* Examples: false positive results, incidentaloma, overdiagnosis, adverse reaction to vaccines and/or medication, borderline conditions, diagnostic cascade, complications of examinations such as infection, allergic reaction to medication or contrast, biopsy complications, endoscopy with viscera perforation etc. Source: adapted from Gray 37.

these potential harms are not properly evaluated. For example, in cancer screening, wherein the spectrum of harm is very significant in group D, they are commonly not measured in their entirety in clinical trials 41 . Additionally, when they are measured in large systematic reviews and metaanalyses, scientific articles usually do not include such reviews 35 . This is a common occurrence in specialist medical journals rather than in general practitioner journals. The former lower reporting rates of potential harms attributed to preventive initiatives, reflecting possibly a conflict of interest 42 . This makes it difficult to compare group D with groups $\mathrm{A}+\mathrm{C}$ with regards to the harm/benefits net balance, exposing asymptomatic people to unnecessary harm.

A thorough evaluation of the harm caused by preventive interventions should not only include quantitative data, but also explore its relevance and severity for patients. Disease screening generally creates a range of by-products that can affect individuals' subjectivities. For instance, psychological problems may occur due to false positive results, a false sense of security from false negative results, and the production of borderline situations. These borderline by-products require a close medicalized monitoring of previous healthy people as in the case of cervical intraepithelial neoplasia (CIN I, II and III), glycose intolerance, sub-clinical hypothyroidism, and so on. Additionally, there may be physical consequences that arise as a result of preventive treatments derived from disease screening 43 . For example, in prostate cancer screening the iatrogenic harms include lifelong infertility, urinary incontinence and impotence 44 . These harms are optimistically estimated to occur in 20 overtreated patients for every beneficiary 45 . As part of the prostate screening process, healthy men that undergo prostate biopsies are exposed to complications that, although rare, can potentially require hospital admission ${ }^{44}$. In the case of breast cancer screening, harms include surgical mutilation, chemotherapy or radiation in a large proportion of overtreated women. This range from 346 to 1047 overdiagnosed women for every breast cancer death prevented due to an early treatment. As a result of exposure to radiation therapy, women with low susceptibility of breast cancer death are exposed to increased mortality due to both heart disease and lung cancer 47 . Thus, for every 2,000 women screened over 10 years, a woman will have her life saved by mammogram screening; however, ten women will be overdiagnosed and overtreated. Moreover, 200 women will experience significant psychological distress including anxiety and uncertainty due to false positive screening results 47 .

The screening of other non-cancer clinical conditions (diabetes, hypertension, osteoporosis, hypothyroidism, obesity, etc.) and the intervention in asymptomatic "preclinical" states contribute greatly to the problem of prevention. Instances of adverse effects of preventative drugs have become more common as large numbers of people have to take them for the rest of their lives. This represents changes in disease diagnostic criteria and/or reduction in high-risk cut-off points for medical intervention, as well as an associated burden of chronic disease conditions of an aged population profile. This context facilitates and/ or leads to polypharmacy in clinical practices, amplifying and complexifying the adverse effects of drugs as they are more numerous and more serious, especially in the elderly 48 .

The aspects and differences mentioned above entail principles and moral values that intermesh technical and ethical or bioethical issues. In Brazil, as well as internationally, the bioethical approach of Principlism has been widely used as guidance for professionals and users of health services ${ }^{49}$. Beauchamp \& Childress's four principles (respect for the person's autonomy, nonmaleficence, beneficence, and justice) 50 were 
proposed to be a practical guidance for conflict resolution and decision-making processes by health professionals in clinical settings and for policy-makers when setting up health services. The limitations and problems of the bioethical approach of Principlism are well known and include unsustainable universalism and idealism. The latter entails an individual free from social constraints, forgetting that in the context of social inequalities, individuals cannot fully exercise their freedom and autonomy. Nevertheless, for the strict purpose discussed in this article, the use of bioethical principles is appropriate and unproblematic. Their mutual relationship makes possible a consistent discussion for balancing their application in the two general situations in focus: clinical care (present illness) and prevention (future illness) 51.

As previously discussed, the exposure of asymptomatic people to a range of adverse effects and potential harms highlights that in preventive interventions the principle of non-maleficence should override that of benevolence. In this regard, the adoption of preventive actions requires greater scrutiny and rigor, moving towards a more skeptical and conservative attitude towards them. In other words, health professionals and policy-makers should be less enthusiastic and more cautious about the implementation of preventive interventions whether they are diagnostic or therapeutic. The requirements for recommending preventive interventions are higher as the potential iatrogenic harms are not balanced by the compensation of cure, control or the alleviation of patients' complaints. The benefits in prevention are the probabilistic potential of either disease or premature death avoidance for a small group of individuals that would become ill in the future (the beneficiary). However, this is performed at the expense of a larger universe of healthy people (present and future) being continuously exposed to biomedical preventative interventions and their associated potential harms 37 .

Norman 43 (p. 106) synthesized this context in a precise and powerful way: in disease screening: “'many are called, but few are chosen...,'but many will need to suffer for very few to be cured". Therefore, in preventive initiatives the imperative of not causing harm (which should be nil or minimal, if present 37,38 ) outweigh the prospect of producing benefits. Although the patient's future health condition is largely unknown, the accountability for implementing preventive actions and their outcomes is not. It falls on the shoulders of professionals and health systems. Thus, the criteria for implementation require transparency, a high degree of safety, based not only on potential ben- efits, but also on their ability to not cause harm. This greater security and absence of clinical pressure for implementing a preventive intervention makes the management of uncertainty qualitatively different in prevention. Given the persistent doubt about the reliability of the evidence of a preventive intervention, we should not act or recommend it; that is: "in doubt leave it out". The immense asymmetry between the requirements for recommending preventive interventions and that of clinical care supports this statement. If there is doubt about the net harm/benefit ratio, this should be enough to not recommend any preventive initiative 35 (Table 2).

The distinction between present and future illness allows for the recognition of specific preventive actions in asymptomatic people (in which the illness that affects a person's life is located in the future), as a group of situations in which the potential harm is much greater. Blurring this distinction sets a barrier for prioritizing P4 actions. Thus, a key step in operationalizing P4 entails highlighting and classifying disease prevention actions as a "red flag". This is a term commonly used in medicine to designate characterizing signs and symptoms of more serious conditions that require further action or close attention.

In addition, the further in the future that a clinically significant disease outcome is located, the greater the need for P4 52 due to the greater complexity and degree of indeterminacy involved in individuals' health-disease processes of known risk factors susceptible of specific interventions. But more importantly, the risk of harming individuals' health is also the greater, as a consequence of the limitations of the current biomedical model. A typical example of the biomedical model's failure, that has practical consequences, was the abusive use of hormone replacement therapy (HRT) in women as a primary prevention initiative. In preliminary studies, HRT showed potential cardiovascular preventive effect based on improvements in women's lipid profile. However, it took several years for a large, good quality clinical trial 53 to demonstrate completely the opposite trend: an increase in cardiovascular mortality. This study changed the clinical practice by recommending against the HRT as a preventive intervention for symptomless women 38 .

Moreover, the more distant in the future the benefits, the greater the chance of harm to patients' health, as continuous and repeated preventive actions over time multiply the chances of a harmful event. This occurs in many situations, such as organized and opportunistic screening programmes, check-ups, and health service 
Differences between clinical care and disease prevention.

\begin{tabular}{|c|c|c|}
\hline & Clinical care & Prevention \\
\hline Guarantee of results & $\begin{array}{l}\text { Not required What is required is the } \\
\text { professionals' technical commitment and } \\
\text { ethical integrity when performing a diagnostic } \\
\text { and therapeutic action. }\end{array}$ & $\begin{array}{l}\text { Required There should be clear evidence of beneficial results as } \\
\text { preventive interventions affect the lives of asymptomatic individuals. } \\
\text { Professionals and policy-makers are accountable for any harm } \\
\text { resulting from preventive actions }\end{array}$ \\
\hline Harm tolerance threshold & $\begin{array}{l}\text { Greater Balanced by professionals' benevolent } \\
\text { duty to cure, control, and relieve patients' } \\
\text { illness/pain }\end{array}$ & $\begin{array}{l}\text { Nil or minimal The harm/benefit ratio should be clear, showing } \\
\text { no or minimal harm. This is the main criterion for adopting or } \\
\text { recommending a preventive intervention, and not its potential benefit }\end{array}$ \\
\hline Uncertainty management & $\begin{array}{l}\text { When in doubt about a biomedical } \\
\text { intervention, a mutual decision can be agreed } \\
\text { on to intervene guided by the patients' safety } \\
\text { and the prospect of improved wellbeing }\end{array}$ & $\begin{array}{l}\text { When in doubt about the harm/benefit ratio of preventive } \\
\text { interventions, do not recommend or adopt them. The risk of } \\
\text { harming is significantly higher in prevention to justify its adoption for } \\
\text { a small group of individuals to harvest the benefits in the future. Non- } \\
\text { maleficence should take precedence over beneficence }\end{array}$ \\
\hline
\end{tabular}

Note: elaborated by the authors.

"routine lab-tests". The multiplication of harmful events occurs via cascades of interventions 54,55 that increase proportionately as a result of repetitive preventive interventions. This process facilitates unnecessary medicalization, expanding its iatrogenic effects beyond the clinical setting to those social and cultural contexts 56 .

The occurrence of incidentalomas is another potential result of this type of preventive initiative. Incidentalomas are abnormal findings derived unintentionally from clinical investigations or resulting from "routine examinations" or check-ups, generally involving imaging tests. The population has what has been called a "diseases reservoir" 57 . With the availability and excessive use of more sensitive sophisticated bio-technological diagnostic equipment, this reservoir has become a source of "pseudo-disease" production 58 . In the absence of medical examinations, the immensity of these incidental findings (pseudo-diseases) would not have existed and/ or harmed patients. Contrary to common sense and biomedical assumptions, in most cases, incidentalomas do not have clinical consequences 59. However, they contribute to overdiagnosis. This challenges medical practice, since incidentalomas occur in both clinical investigations and disease prevention scenarios. The distinction between clinical care and prevention of future disease conditions can help reduce the occurrence of incidentalomas, by means of $\mathrm{P} 4$ initiatives.

\section{Caregivers' conservatism: "when in doubt leave it out"}

The distinction between disease prevention and illness care, as a founding principle, requires a subjective, symbolic, emotional, and attitudinal shift when considering and/or deciding on disease preventive recommendations. In other words, it requires that "the activism of caregivers" (pro-interventionist) in clinical care transforms into "the conservatism of caregivers" (anti-interventionist) when considering preventive actions. The former is understandable and acceptable in situations where professionals and patients are trying to heal and/or mitigate patients' suffering. The latter implies an attitude of resistance, caution, and reassurance of individuals' integrity in the case of prevention. This shift is consistent with the non-emergency character of preventive actions, which is summarized in Table 2 .

This attitudinal shift should be understood and considered when constructing a responsible proposal for disease prevention management. It requires an ethical and technical approach. This can be simply synthesized for professionals and health systems by following the general principle: "in clinical care, when in doubt, but for patients' wellbeing and safety, one can decide to intervene; whereas, in preventive activities that fall on asymptomatic patients, when in doubt, and for patients' wellbeing and safety, leave it out". This rule of thumb is particularly important in those preventive actions with a high risk of harm such as the use of "preventive" drugs, invasive procedures, and professionalized care. These preventive initiatives can unfold in a cascade of 
interventions 54 , carrying with it great potential of causing harm and medicalization.

Nonetheless, commonly in primary care service clinical care situations, health professionals work in a low-disease prevalence context when compared to hospital-based practice. Thus, even in clinical care, a less interventionist and parsimonious approach to patients' complaints is possible in general practice. In this context, the development of illnesses might improve (or diagnoses clarified) simply by a close follow up, sometimes associated with conservative measures and/or synergic physiological support. This is referred to usually as watchful waiting 40 , which entails a close relationship between the time framework and patient symptomatology (safety net), together with the skillful use of the therapeutic effects of the health professional-patient relationship 4 .

The adoption of a more skeptical and conservative approach to preventive interventions usually faces as much resistance from society as it does from biomedical professionals. The increase in the population's longevity and its associated chronic disease burden represent a challenge to the biomedical model. This produces unmet expectations to both health professionals and users of health systems, generating a collective feeling of frustration. Moreover, overdiagnosis and overtreatment generate the so-called "paradox of popularity", which tends to hide the harmful effects of disease prevention activities 34. The "paradox of popularity" is a result of great number of people undergoing biomedical interventions to which most of them would not have suffered (supposedly) in the future. This creates a feeling that health is being "optimised" 60 . In the case of cancer screening, all diagnosed and treated patients believe they are cured of an early cancer and their lives saved by a biomedical intervention. In reality, however, most of them are being overdiagnosed and consequently harmed without the potential benefit, as they would not have developed the disease.

The "paradox of popularity" and society's collective frustrations with biomedicine generate more demands for preventive actions, reinforcing the uncritical pro-activism attitude and naïve apology for prevention at all costs. This context seems to have only increased in the twenty-first century, making the attitudinal change mentioned above even more necessary. The adoption of individualized preventive activities by clinical care has expanded the role of prevention in clinical settings. This requires attitudinal changes that are neither fully exercised by primary health care professionals nor promoted by public health systems (Figure 1).

Figure 1

Implications of the prevention-cure distinction.

- Wake up health professionals from the current preventivist "somnambulism" that began in the second half of the 20 th
century and has been further entrenched due to biotechnological advancements in the 21 st century.
- Improve the ethical and technical criteria for implementing preventive activities.
- Allow the development of a model of care focused on the individual's present needs that does not obstruct the access
to those "real" diseased individuals in need of professional care 6,11 .
- Counterbalance the growing trends and obsessions that demand for more preventive actions in an aging population,
allowing for alternative approaches that overcome the biomedical model's inability to deal with the burden of
chronic diseases.
- Revaluing the dignity in clinical care (illness) as it opens the way for its improvement by improving health professional-
users relationships and making them more personal.
- Stimulate a reverse movement in health care: minimal intervention with maximum quality.

Note: elaborated by the authors. 
The differences between the clinical care and preventive actions require a distinct approach to biomedical knowledge, specifically to EBM. In the case of clinical care for illnesses, professionals' diagnostic or therapeutic decisions are partially guided by EBM. The greater need for action in clinical care means that professionals have more freedom as their clinical experience and biomedical knowledge contribute to decision-making processes. In this context, evidencebased medicine is just one important source of information guiding health professionals, but its absence or inaccessibility does not mean any hindrance to the flow of biomedical care.

Nevertheless, in the case of preventive actions in asymptomatic people, the situation is very different, almost the opposite. The strict requirements in prevention compel us to be skeptical and resistant towards the interventionist biomedical tradition and its knowledge. Unlike in illness situations, in prevention there is no immediate pressure for action as people might be exposed to iatrogenic harm without any potential benefits (Table 1). Therefore, the professional's experience, field of expertise, and accumulated knowledge in biomedicine should be subservient to scientific evidence derived from high-quality studies and their meta-analyses, focused on final rather than intermediary outcomes that measure both benefits and harms 61,62 . This should be the major technical criterion necessary to satisfy the highest requirements of a quality health assurance framework. This assurance can only be provided by reliable and up-to-date scientific evidence that addresses the outcomes of preventive interventions such as quality of life, morbidity, specific and global mortality of preventable diseases, and so on. This comprises studies carried out in controlled environments (clinical trials), as well as in observational studies after years of applying preventive activities in real populations.

Therefore, the evidence focused on final outcomes has become the backbone for decisionmaking processes both by health professionals and policy-makers on specific preventive actions in asymptomatic individuals. Unlike in clinical care, such high quality medical evidence is (and should be) practically the major guiding criteria for decisions for recommending preventive interventions. Thus, for adopting preventive recommendations, policy-makers and health professionals are almost completely dependent on quality standards of EBM.

However, this context becomes more complex as trust in the EBM paradigm has been eroded by the growing influence of big pharmaceutical corporations. There is a growing recognition that $\mathrm{EBM}$ is not value-free and its research agenda is made or strongly influenced by different interests 63. Recently, EBM was portrayed as a "movement in crisis" 64 and there has been a great interest in the excessive amounts of medicine related to overdiagnosis and overtreatment 65 . The critiques do not address EBM's theoretical framework, but question its close connection with the pharmaceutical and biotechnology industries. These industries intervene in various ways in clinical trials protocols via: (1) manipulation of drug dose-response in the intervention and control groups; (2) selective recruitment of patients more likely to have a positive response in the study's intervention arm; and (3) the adoption of substitute (intermediary) disease outcomes that have little impact on peoples' morbidity and mortality rates. Thus, the lack of transparency in the research protocols, as well as the omission of negative results from clinical trials, creates important biases in the biomedical literature 64 .

A recent debate about a clinical guideline for the prevention of cardiovascular disease in the UK exemplifies the concern about pharmaceutical industry influences in its development. The new recommendations from the National Institute of Health and Care Excellence (NICE) lowered the cut-off point for prescribing statins from $20 \%$ to $10 \%$ of 10 -year mortality cardiovascular risk 66 , based on unreliable evidence 67,68 . The expansions of statin usage convert healthy people into almost patients who need constant medical monitoring. By re-signifying the usage of existing drugs in the market, the pharmaceutical industries increase their profits 25 . This adds greater complexity to policy-makers' and health professionals' decision-making processes given the uncertainties and inconsistencies in biomedical evidence.

The different weight that EBM has in clinical practice and prevention, coupled with the uncertainties around transparency in research protocols, significantly reinforces the need for a different approach in attitudes towards prevention activities. Firstly, the caregivers' conservatism (anti-interventionist) should be based on scientific skepticism with regards to EBM's high methodological standards and ethical principles, highlighting any source of conflict of interest. This includes transparent protocols for clinical trials and the availability of primary research data that can be scrutinized by independent researchers. Unfortunately, this type of information is usually protected by the industry's "market law" of intellectual property and patent requirements 64 . Secondly, economic influences on EBM intensify the asymmetry in deciding about introducing a preventive initiative, strengthening the principle that when in doubt about preventive ac- 
tivities, policy-makers and professionals should not recommend them.

Additionally, other ethical, technical, social and institutional criteria must be met for recommending preventive interventions in asymptomatic people, such as the disease screening criteria developed by Jungner \& Wilson 69,70 . Preventive initiatives also require further conceptual nuances and framework such as those proposed by Geoffrey Rose 71,72. This article has addressed a small spectrum of preventive activities: those that add some artificial factors (e.g. statins) to individuals in the hope of conferring them protection, referred by Rose 71 as "additive" preventive actions. "Additive" prevention encompasses a high risk of medicalization and iatrogenic effects. However, there is another range of preventive activities that aims to remove or reduce exposure to artificial risk factors and life's excesses, faults or deviations such as inadequate living and working conditions, including eating habits, drinking, leisure, rest, etc. These "subtractive" preventive actions entail restoring the environment and social conditions that favor salutogenic ways of living. The scientific basis of these recommendations is relatively unproblematic since it aims to reduce tobacco and excessive alcohol consumption, physical inactivity, processed food intake and food pesticide usage, air pollution, overwork and stress, sleep deprivation, socio-economic deprivation, and so on. These measures "can be presumed to be generally safe, and they can therefore be accepted on the basis of a reasonable presumption of benefit" 67 (p. 94). They are also theoretically consistent and validated by the available evidence and scientific knowledge. There is a relative consensus of the crucial importance in health promotion at the individual and societal levels of this type of prevention. However, even in "subtractive" preventive actions, Rose 71 is emphatic about the superiority of these approaches as a population strategy rather than as andividualized intervention. The latter is strongly influenced by social and cultural forces that challenge individuals' capacities for modifying their behavior. Hence, when it comes to prevention, a greater skepticism and resistance is required in "additive" preventive measures with the emphasis shifting towards "subtractive" preventive activities, whose safety and benefit are incomparably greater.
The conceptual and attitudinal differentiation in regards to additive prevention and clinical care is just one step among many others needed to challenge the contemporary overemphasis on prevention, i.e. hyperpreventivism. The latter is fostered by powerful and complex socio-political and economic influences. This results in excessive and undesirable commercial and industrial influences in healthcare systems' technical and clinical care practices that tend to treat health as a commodity 72 . Although P4 is not a major component for changing society's current medicalized status, it is a necessary step for re-signifying the attitudes and subjectivities of health professionals, policy-makers, and users of public health systems 33 . This could lead to a better and more balanced relationship with biomedical technologies.

\section{Conclusion}

Biomedical "additive" preventive activities in asymptomatic cases are fundamentally distinct from clinical care, and must remain so. They differ in regard to uncertainty management (which is more tolerated in clinical care) and the re quirement in preventive activities for a net positive harm/benefit ratio. From the perspective of $\mathrm{P} 4$, this separation is the bedrock that should underpin any theoretical, technical, and ethical consideration of both policy-makers and health professionals when deciding about preventive actions. This implies the adoption of a conservative care attitude (anti-interventionist) in "additive" preventive actions, especially, when they involve invasive diagnostic interventions (that may trigger cascades of interventions) and treatment based on physical-chemical biomedical technologies, such as drugs, vaccines, and so on. This distinction is an unavoidable prerequisite for practicing quaternary prevention in regards to preventive activities that have far reaching consequences: it implies revaluing patient care in the now (amplifying the present) and considering with great caution and strict ethical-technical criteria individual interventions aiming at preventing future disease outcomes among asymptomatic patients. 


\section{Contributors}

C. D. Tesser designed the study, drew up the first version, carried out critical revisions and wrote up the final version. A. H. Norman participated in the discussion and critical revision of content, revision of the text and write up of the final version.

\section{Acknowledgments}

We would like to thank Mr. Jim Coxon from the Anthropology Department of Durham University who kindly did the proof reading of our article.

\section{References}

1. Jamoulle M. The four duties of family doctors: quaternary prevention - first, do no harm. Hong Kong Practitioner 2014; 36:72-7.

2. Jamoulle M. Quaternary prevention: first, do not harm. Rev Bras Med Fam Comunidade 2015; 10:1-3.

3. Starfield B, Hyde J, Gérvas J, Heath I. The concept of prevention: a good idea gone astray? J Epidemiol Community Health 2008; 62:580-3.

4. Norman AH, Tesser CD. Prevenção quaternária na atenção primária à saúde: uma necessidade do Sistema Único de Saúde. Cad Saúde Pública 2009; 25:2012-20.

5. Foucault M. Microfísica do poder. 18a Ed. Rio de Janeiro: Edições Graal; 1979.

6. Illich I. Limits to medicine: medical nemesis: the expropriation of health. London: Marion Boyars; 1976.
7. Zola IK. Medicine as an institution of social control. Sociol Rev 1972; 20:487-504.

8. Szasz TS. The myth of mental illness: foundations of a theory of personal conduct. New York: Harper \& Row; 1974.

9. Skrabanek P. Why is preventive medicine exempted from ethical constraints? J Med Ethics 1990; 16:187-90.

10. Skrabanek P. The death of humane medicine and the rise of coercive healthism. London: Social Affairs Unit; 1994.

11. Clarke AE, Mamo L, Fosket JR, Fishman JR, Shim JK. Biomedicalization: technoscience, health, and illness in the U.S. Durham: Duke University Press; 2010.

12. Leavell H, Clark EG. Medicina preventiva. São Paulo: McGrawHill do Brasil; 1976. 
13. Almeida Filho N. A clínica e a epidemiologia. Salvador: APCE/Rio de Janeiro: Abrasco; 1992.

14. Ayres JRCM. Sobre o risco: para compreender a epidemiologia. São Paulo: Editora Hucitec; 1997.

15. Doran E, Hogue C. Potency, hubris and susceptibility: the disease mongering critique of pharmaceutical marketing. Qual Rep 2014; 19:1-18.

16. Moynihan R, Heath I, Henry D. Selling sickness: the pharmaceutical industry and disease mongering. BMJ 2002; 324:886-90.

17. Moynihan R, Henry D. The fight against disease mongering: generating knowledge for action. PLoS Med 2006; 3:e191.

18. Moynihan R, Doran E, Henry D. Disease mongering is now part of the global health debate. PLoS Med 2008; 5:e106.

19. Heath I. In defence of a national sickness service. BMJ 2007; 334:19.

20. Gérvas J, Starfield B, Heath I. Is clinical prevention better than cure? Lancet 2008; 372:1997-9.

21. Norman AH, Tesser CD. Access to healthcare in the Family Health Strategy: balance between same day access and prevention/health promotion. Saúde Soc 2015; 24:165-79.

22. The Criteria Committee of the New York Heart Association. Diseases of the heart and blood vessels: nomenclature and criteria for diagnosis. $6^{\text {th }} \mathrm{Ed}$. Boston: Little Brown; 1964.

23. Hunt SA, Baker DW, Chin MH, Cinquegrani MP, Feldman AM, Francis GS, et al. ACC/AHA guidelines for the evaluation and management of chronic heart failure in the adult: executive summary: a report of the American College of Cardiology/American Heart Association Task Force on Practice Guidelines (Committee to Revise the 1995 Guidelines for the Evaluation and Management of Heart Failure). J Am Coll Cardiol 2001; 38:2101-13.

24. Bocchi EA, Marcondes-Braga FG, Ayub-Ferreira SM, Rohde LE, Oliveira WA, Almeida DR, et al. III Diretriz Brasileira de Insuficiência Cardíaca Crônica. Arq Bras Cardiol 2009; 93(1 Suppl 1):1-71.

25. Montori V, Isley W, Guyatt G. Waking up from the dream of preventing diabetes with drugs. BMJ 2007; 334:882-4.

26. Jensen MC, Brant-Zawadzki MN, Obuchowski N, Modic MT, Malkasian D, Ross JS. Magnetic resonance imaging of the lumbar spine in people without back pain. N Engl J Med 1994; 331:69-73.

27. Currie CJ, Peters JR, Tynan A, Evans M, Heine RJ, Bracco OL, et al. Survival as a function of HbAlc in people with type 2 diabetes: a retrospective cohort study. Lancet 2010; 375:481-9.

28. Borrell-Carrió F, Suchman AL, Epstein RM. The biopsychosocial model 25 years later: principles, practice, and scientific inquiry. Ann Fam Med 2004; 2:576-82.
29. Almeida ELV. As razões da terapêutica: empirismo e racionalismo na medicina. Niterói: Eduff; 2002.

30. Starfield B. Is US health really the best in the world? JAMA 2000; 284:483-5.

31. Luz MT. Natural, racional, social: razão médica e racionalidade científica moderna. Rio de Janeiro: Campus; 1988.

32. Starfield B. The hidden inequity in health care. Int J Equity Health 2011; 10:15.

33. Welch HG, Schwartz L, Wolosin S. Overdiagnosed: making people sick in the pursuit of health. Boston: Beacon Press; 2011.

34. Bulliard JL, Chiolero A. Screening and overdiagnosis: public health implications. Public Health Rev 2015; 36:1-5.

35. Tesser CD, d'Ávila TLC. Por que reconsiderar a indicação do rastreamento do câncer de mama? Cad Saúde Pública 2016; 32:e00095914.

36. Bayer R, Galea S. Public health in the precisionmedicine era. N Engl J Med 2015; 373:499-501.

37. Gray JAM. New concepts in screening. Br J Gen Pract 2004; 54:292-8.

38. Sackett D. The arrogance of preventive medicine. CMAJ 2002; 167:363-4.

39. Bauer S. Modelling population health reflections on the performativity of epidemiological techniques in the age of genomics. Med Anthropol Q 2013; 27:510-30.

40. Kloetzel K. Medicina ambulatorial: princípios básicos. São Paulo: EPU; 1999.

41. Heleno B, Thomsen MF, Rodrigues DS, Jorgensen $\mathrm{KJ}$, Brodersen J. Quantification of harms in cancer screening trials: literature review. BMJ 2013; 347:f5334.

42. Rasmussen K, Jørgensen KJ, Gøtzsche PC. Citations of scientific results and conflicts of interest: the case of mammography screening. Evid Based Med 2013; 8:83-9.

43. Norman AH. Medical ethics and screening: on what evidence should we support ourselves? Rev Bras Med Fam Comunidade 2014; 9:105-7.

44. Ilic D, Neuberger MM, Djulbegovic M, Dahm P. Screening for prostate cancer. Cochrane Database Syst Rev 2013; (1):CD004720.

45. Welch HG, Albertsen PC. Prostate cancer diagnosis and treatment after the introduction of prostatespecific antigen screening: 1986-2005. J Natl Cancer Inst 2009; 101:1325-9.

46. Jørgensen KJ, Zahl PH, Gøtzsche PC. Overdiagnosis in organised mammography screening in Denmark: a comparative study. BMC Women's Health 2009; 9:36.

47. Gøtzsche PC, Jørgensen KJ. Screening for breast cancer with mammography. Cochrane Database Syst Rev 2013; (6):CD001877. 
48. Gómez Santana MC, Gavilán-Moral E, VillafainaBarroso A, Jiménez-de Gracia L. Prescripción prudente y deprescripción de fármacos como herramientas para la prevención cuaternaria. Rev Bras Med Fam Comunidade 2015; 10:1-8.

49. Diniz D, Bellezi GD, Garrafa V. Bioethics in Brazil. Bioethics 1999; 13:244-8.

50. Beauchamp TL, Childress JF. Principles of biomedical ethics. $4^{\text {th }}$ Ed. New York: Oxford University Press; 1994.

51. Dejeanne S. Os fundamentos da bioética e a teoria principialista. Thaumazein 2011; IV(7). http:// sites.unifra.br/Portals/1/ARTIGOS/nro_06/SOL ANGE.pdf.

52. Norman AH, Tesser CD. Quaternary prevention: the basis for its operationalization in the doctorpatient relationship. Rev Bras Med Fam Comunidade $2015 ; 10: 1-10$.

53. Writing Group for the Women's Health Initiative Investigators. Risks and benefits of estrogen plus progestin in healthy postmenopausal women. Principal results from the Women's Health Initiative randomized controlled trial. JAMA 2002; 288:321-33.

54. Gérvas J, Pérez-Fernández M. El efecto cascada: implicaciones clínicas, epidemiológicas y éticas. Med Clin 2002; 118:65-7.

55. Gérvas J. Moderación en la actividad médica preventiva e curativa: cuatro ejemplos de necesidad de prevención cuaternaria en España. Gac Sanit 2006; 20 Suppl 1:127-34.

56. Illich I. A expropriação da saúde: nêmesis da medicina. 4a Ed. São Paulo: Nova Fronteira; 1981.

57. Welch HG. Should I be tested for cancer? Maybe not and here's why. Berkeley: University of California Press; 2004.

58. Welch HG, Black WC. Overdiagnosis in cancer. J Natl Cancer Inst 2010; 102:605-13.

59. Mariño MA. Incidentalomas: concept, relevance and challenges for medical practice. Rev Bras Med Fam Comunidade 2015; 10:1-9.

60. Raffle AE, Gray JAM. Screening evidence and practice. Oxford: Oxford University Press; 2007.

61. Shaughnessy AF, Slawson DC, Bennett JH. Becoming an information master: a guidebook to the medical information jungle. J Fam Pract 1994; 39:489-99
62. Slawson DC, Shaughnessy AF, Bennett JH. Becoming a medical information master: feeling good about not knowing everything. J Fam Pract 1994; 38:505-13.

63. Kelly M, Heath I, Howick J, Greenhalgh T. The importance of values in evidence-based medicine. BMC Med Ethics 2015; 16:69.

64. Greenhalgh T, Howick J, Maskrey N. Evidence based medicine: a movement in crisis? BMJ 2014; 348:g3725.

65. Heath I. Overdiagnosis: when good intentions meet vested interests - an essay by Iona Heath. BMJ 2013; 347:f6361.

66. National Institute for Health and Care Excellence. Cardiovascular risk assessment and the modification of blood lipids for the primary and secondary prevention of cardiovascular disease. London: National Institute for Health and Care Excellence; 2014.

67. Abramson JD, Rosenberg HG, Jewell N. Wright JM. Should people at low risk of cardiovascular disease take a statin? BMJ 2013; 6123:1-5.

68. Lenzer J. Majority of panelists on controversial new cholesterol guideline have current or recent ties to drug manufacturers. BMJ 2013; 6989:1-2.

69. Wilson JMG, Jungner G. Principios y métodos del examen colectivo para identificar enfermedades. Geneva: Organización Mundial de la Salud; 1969. (Cuadernos de Salud Pública, 34).

70. Andermann A, Blancquaert I, Beauchamp S, Dery V. Revisiting Wilson and Jungner in the genomic age: a review of screening criteria over the past 40 years. Bull World Health Organ 2008; 86:317-9.

71. Rose G. Sick individuals and sick populations. Int J Epidemiol 1985; 14:32-8.

72. Rose G. The strategy of preventive medicine. Oxford: Oxford University Press; 1993.

73. Rylko-Bauer B, Farmer P. Managed care or managed inequality? A call for critiques of market-based medicine. Med Anthropol Q 2002; 16:476-502. 


\section{Resumo}

O artigo propõe que a distinção entre os cuidados clínicos (para a doença atual) e a prevenção de doenças futuras é essencial para a prática da prevenção quaternária. Os autores argumentam que uma confusão persistente vem transformando pessoas saudáveis em "doentes" através de mudanças nos critérios de classificação de doenças elou de pontos de corte para definir estados de risco elevado. Isso desvia os recursos para atenção em saúde dos mais necessitados e aumenta o risco de dano iatrogênico a pessoas saudáveis. A distinção se baseia em: (a) o manejo da incerteza (mais flexível no cuidado de doentes); (b) a garantia de benefício (exigida apenas no caso da prevenção) e (c) tolerância para o dano (nula ou mínima na prevenção). Isso implica em diferenças de atitude no processo decisório: maior ceticismo, cientificismo e resistência em relação à ação preventiva. Tais aspectos devem ser embasados em evidências científicas de alta qualidade em relação aos desfechos, e que apresentem correlação positiva entre dano e beneficio.

Prevenção Quaternária; Prevenção de Doenças; Cuidados Médicos

\section{Resumen}

Este artículo sostiene que la distinción entre el cuidado médico (enfermedad) y la prevención de futuras enfermedades es esencial para la práctica de la prevención cuaternaria. Los autores discuten que el conflicto en curso entre los cuidados médicos y la prevención transforma las personas sanas en enfermas, debido a los cambios en los criterios de clasificación y/o puntos de corte para definir situaciones de alto riesgo. Esto produce una desviación de los recursos sanitarios de quienes necesitan realmente el cuidado médico, e incrementa el riesgo de daño iatrogénico en personas sanas. Esta distinción está basada en: (a) gestión de la incertidumbre (más flexible cuando se cuida de personas enfermas); (b) garantía de beneficio (requerida sólo en prevención); (c) tolerancia al daño (nula o mínima en prevención). Esto implica diferencias actitudinales en el proceso de toma de decisiones: gran escepticismo, cientificismo y resistencia a la acción preventiva. Estos aspectos deberían estar basados en evidencia científica de alta calidad sobre los resultados finales que mues tren una razón positiva entre daño y beneficio.

Prevención Cuaternaria; Prevención de Enfermedades; Atención Médica
Submitted on $24 / \operatorname{Jan} / 2016$

Final version resubmitted on 27/May/2016 Approved on 20/Jul/2016 